\title{
PENGARUH BAGI HASIL TERHADAP SIMPANAN MUDHARABAH PADA KSPPS BMT AMANAH RAY MEDAN
}

\author{
Aulia Putri, Rusdiono, Dedi Wahyudi \\ Alumni Sekolah Tinggi Ilmu Manajemen Sukma \\ Program studi Manajemen, Sekolah Tinggi Ilmu Manajemen \\ rusdiono0670@gmail.com, dediw7084@gmail.com
}

\begin{abstract}
The purpose of this study is to determine whether there is influence for the results of the mudharabah savings on KSPPS BMT Amanah Ray Medan partially. The object of this research is KSPPS BMT Amanah Ray Medan which data sharing report and mudharabah deposit obtained directly from KSPPS BMT Amanah Ray Medan. Data analysis method used in this research is quantitative descriptive research, while the analysis model used in this research is simple linear regression analysis. Hypothesis testing of this research using detemination coefficient test (R2) and partial test ( $t$ test) using SPSS Version 22.0 as data processing. The results showed that partially for the results have a positive and significant effect on mudharabah savings on KSPPS BMT Amanah Ray Medan. Keywords : Profit Sharing, Mudharabah and KSPPS BMT Amanah Ray
\end{abstract}

\section{PENDAHULUAN}

Pada saat ini, sistem keuangan di Indonesia tidak hanya mengunakan konvensional (bunga), tapi juga sudah menggunakan sistem syariah (bagi hasil). yang diterapkan dalam sistem keuangan syariah. Masyarakat Indonesia hanya mengetahui bunga sebagai bentuk balas jasa yang diterapkan oleh bank konvensional. Pada tahun 1990 Majelis Ulama Indonesia (MUI) membentuk kelompok kerja untuk mendirikan Bank Islam di Indonesia. Sebagai hasil kerja Tim Perbankan MUI adalah berdirinya bank syariah pertama di Indonesia yaitu PT. Bank Muamalat Indonesia. Masyarakat yang mulai mengenal dan memahami bagi hasil yang non riba maka masyarakat semakin tertarik untuk menyimpan dananya pada setiap bank yang berbasis syariah, hal ini ditandai dengan semakin banyaknya bank konvensional yang mendirikan bank syariah seperti BNI syariah, BRI Syariah, Mandiri syariah dll. Dengan adanya kesadaran masyarakat Indonesia yang mayoritas berpenduduk muslim yang melarang riba hal ini mendasari bagi hasil lebih dipilih dari pada bunga. Simpanan mudharabah merupakan salah satu produk lembaga keuangan syariah yang didalamnya tidak ada unsur riba, Sebagai lembaga keuangan Syariah, lembaga keuangan harus berpegang teguh pada prinsip-prinsip Syariah yang mengunakan bagi hasil sebagai bentuk balas jasa kepada nasabah yang telah menyimpankan dananya dalam bentuk simpanan mudharabah akan tetapi dalam praktiknya banyak orang selalu mencari keuntungan dan manfaat yang lebih baik dari tiap produk yang ditawarkan oleh lembaga-lembaga keuangan, baik lembaga keuangan bank dan lembaga keuangan non bank. Oleh karena itu lembaga-lembaga keuangan saling berkompetisi menawarkan produkproduk yang dimilikinya sesuai dengan minat yang diinginkan oleh calon nasabah. Produk yang ditawarkan pada umumnya hampir sama, tetapi memiliki perbedaan seperti tingkat suku bunga/bagi hasil.

\section{Perumusan Masalah}

Perumusan masalah penelitian ini yaitu apakah ada pengaruh bagi hasil terhadap simpanan mudharabah pada KSPPS BMT Amanah Ray Medan.

\section{Batasan Masalah}

Penelitian ini dibatasi hanya pada simpanan mudharabah dan Data laporan keuangan periode 2012-2016 pada BMT Amanah Ray.

\section{Tujuan Penelitian}

Adapun tujuan penelitian ini adalah untuk mengetahui pengaruh bagi hasil terhadap jumlah simpanan mudharabah pada KSPPS BMT Amanah Ray Medan. 


\section{Manfaat Penelitian}

Manfaat Penelitian ini adalah sebagai berikut:

1. Bagi Peneliti, menambah pengetahuan dan wawasan khususnya berkenaan dengan pengaruh bagi hasil terhadap simpanan mudharabah;

2. Bagi Perusahaan, sebagai bahan masukan mengenai pengaruh bagi hasil terhadap simpanan mudharabah;

3. Bagi STIM Sukma Medan, sebagai masukan yang yang akan berguna bagi mahasiswa/i yang akan mengadakan penelitian dalam bidang kajian yang sama serta sebagai bahan bacaan di perpustakaan STIM Sukma Medan;

\section{METODE PENELITIAN}

\section{Metode Pengumpulan Data}

Metode pengumpulan data yang digunakan dalam penelitian ini adalah Studi Dokumentasi yaitu berupa pengumpulan data yang dilakukan dengan mencari informasi berdasarkan dokumendokumuen peusahaan yang berkaitan dengan penelitian

\section{Definisi Operasional.}

Berdasarkan rumusan masalah, maka variabel-variabel dalam penelitian ini dapat didefinisikan sebagai berikut:

1. Variabel bebas (Variabel independen) adalah variabel yang mempengaruhi variabel terikat, yaitu bagi hasil (X).

2. Variabel bebas (Variabel dependen) adalah variabel yang dipengaruhi variabel bebas, yaitu jumlah simpanan mudharabah (Y).

Operasionalisasi Variabel Penelitian

\begin{tabular}{|c|l|l|l|c|}
\hline No & \multicolumn{1}{|c|}{ Variable } & \multicolumn{1}{|c|}{ Definisi } & \multicolumn{1}{|c|}{$\begin{array}{c}\text { Indikator } \\
\text { ukur }\end{array}$} \\
\hline 1 & $\begin{array}{l}\text { Bagi Hasil } \\
(\mathrm{x})\end{array}$ & $\begin{array}{l}\text { Bagi hasil adalah bentuk return dari } \\
\text { kontrak investasi, dari waktu ke waktu, } \\
\text { tidak pasti dan tidak tetap }\end{array}$ & $\begin{array}{l}\text { Bagi Hasil } \\
\text { yang di } \\
\text { terima oleh } \\
\text { nasabah }\end{array}$ & Nominal \\
\hline 2 & $\begin{array}{l}\text { Jumlah } \\
\text { simpanan } \\
\text { mudharabah } \\
\text { (y) }\end{array}$ & $\begin{array}{l}\text { Simpanan Mudharabah adalah simpanan } \\
\text { atau tabungan pemilik dana yang } \\
\text { penyetornya dan penarikannya dapat } \\
\text { dilakukan sesuai dengan perjanjian yang } \\
\text { telah disepakati sebelumnya }\end{array}$ & $\begin{array}{l}\text { Laporan } \\
\text { Keuangan } \\
\text { Simpanan } \\
\text { Mudharabah }\end{array}$ & Nominal \\
\hline
\end{tabular}

Sumber : (Karim, dalam Timami dan Soejoto, 2013:4), (Muhammad, 2013:14),

\section{Metode Analisis Data}

$$
\text { Rachman dkk, 2013:417) }
$$

Metode analisis data yang digunakan dalam penelitian ini adalah penelitian deskriptif kuantitatif. Sedangkan model analisis yang digunakan dalam penelitian ini adalah analisis regresi linier sederhana dengan model persamaan:

\section{Dimana:}

$$
\mathrm{Y}=\mathrm{a}+\mathrm{b}_{\mathrm{X}}+\mathrm{e}
$$

$\mathrm{Y} \quad=$ Jumlah simpanan Mudharabah

$\mathrm{X}_{1} \quad=$ Bagi hasil

a $\quad=$ Konstanta

$\mathrm{b}_{\mathrm{X}} \quad=$ Koefisien regresi bagi hasil

$\mathrm{e} \quad=$ Error of term (variable yang tidak diteliti)

\section{Kerangka Berpikir}

Bagi hasil adalah bentuk return (perolehan kembalinya) dari kontrak investasi, dari waktu ke waktu, tidak pasti dan tidak tetap. Mudharabah merupakan akad kerja sama antara dua pihak, dimana pihak pertama menyediakan seluruh modal dan pihak lain menjadi pengelola. Penelitian oleh Aziz (2014) menunjukan tingkat bagi hasil berpengaruh positif terhadap simpanan mudharabah. Hasil 
penelitian yang dilakukan oleh Rachman dkk (2013) menunjukan bahwa tingkat bagi hasil berpengaruh positif dan signifikan terhadap simpanan mudharabah.

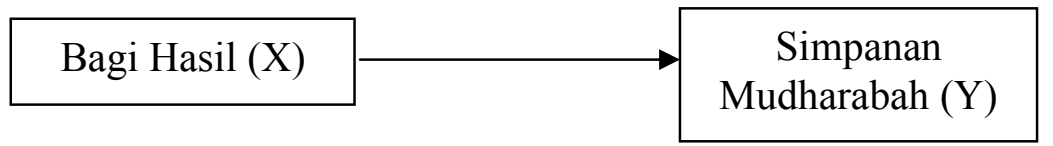

Gambar 1 Kerangka Berpikir

Sumber : Aziz (2014) dan Rachman dkk (2013)

\section{Hipotesis}

"Hipotesis dapat dikatakan kesimpulan sementara, merupaka suatu konstruk (construct) yang masih perlu dibuktikan, suatu keseimpulan yang belum terujii kebenaranya" (Yusuf, 2014:130).

Berdasarkan pengertian diatas, maka hipotesis penelitian ini adalah "ada pengaruh bagi hasil terhadap simpanan mudharabah pada KSPPS BMT Amanah Ray Medan”.

\section{Pengujian Hipotesis}

a. Koefisien determinasi $\left(\mathrm{R}^{2}\right)$

Koefisien determinasi $\left(\mathrm{R}^{2}\right)$ pada initinya mengukur seberapa besar kemampuan model dalam menerangkan variabel terikat. Semakin besar nilai koefisien determinasi (mendekati satu), maka dapat dikatakan bahwa pengaruh variabel bebas $(\mathrm{X})$ adalah besar terhadap variabel terikat (Y).

b. Uji Parsial (Uji t)

Uji parsial (uji t) bertujuan untuk melihat pengaruh bagi hasil terhadap simpanan mudharabah, dengan kriteria:

1. Jika $t_{\text {hitung }} \leq t_{\text {tabel }}$, maka $\mathrm{H}_{0}$ diterima, $\mathrm{H}_{1}$ ditolak, artinya secara parsial penelitian ini tidak berpengaruh;

2. Jika $t_{\text {hitung }}>t_{\text {tabel }}$, maka $\mathrm{H}_{0}$ ditolak, $\mathrm{H}_{1}$ diterima, artinya secara parsial penelitian ini berpengaruh;

\section{HASIL DAN PEMBAHASAN}

Bagi Hasil dan Simpanan Mudharabah

Berdasarkan data yang didapat langsung dari KSPPS BMT Amanah Ray Medan dari tahun 2012 sampai dengan 2016, dapat disajikan bagi hasil dan simpanan mudharabah perusahaan adalah sebagai berikut ini:

Tabel 1 Bagi Hasil dan Simpanan Mudharabah Periode 2012-2016

\begin{tabular}{|c|c|c|c|c|}
\hline \multirow{2}{*}{ Tahun } & \multicolumn{2}{|c|}{2012} & \multicolumn{2}{|c|}{2013} \\
\hline & Bagi Hasil & $\begin{array}{c}\text { Simpanan } \\
\text { Mudharabah }\end{array}$ & Bagi Hasil & $\begin{array}{l}\text { Simpanan } \\
\text { Mudharabah }\end{array}$ \\
\hline Januari & Rp10,050,429.81 & $\mathrm{Rp} 1,827,303,574.83$ & Rp11,658,602.90 & Rp1,892,292,768.59 \\
\hline Februari & Rp10,647,900.00 & $\mathrm{Rp} 1,824,418,247.58$ & Rp10,600,009.00 & Rp1,568,833,502.64 \\
\hline Maret & Rp10,991,636.05 & Rp1,660,455,654.77 & Rp10,724,538.50 & Rp1,621,906,808.58 \\
\hline April & Rp11,467,204.26 & $\mathrm{Rp} 1,836,083,067.53$ & Rp10,785,654.80 & $\mathrm{Rp} 1,787,468,590.90$ \\
\hline Mei & Rp11,535,582.47 & Rp1,928,640,228.60 & Rp9,056,211.00 & Rp1,853,663,431.83 \\
\hline Juni & Rp11,221,191.91 & $\mathrm{Rp} 2,013,946,776.82$ & Rp11,714,009.86 & $\mathrm{Rp} 1,801,037,924.08$ \\
\hline
\end{tabular}




\begin{tabular}{|c|c|c|c|c|}
\hline Juli & Rp11,123,937.68 & Rp1,840,378,982.63 & Rp9,607,071.42 & Rp1,686,997,142.03 \\
\hline Agustus & Rp10,017,302.71 & Rp1,438,377,971.29 & Rp10,839,913.97 & Rp1,185,693,840.26 \\
\hline September & Rp12,529,634.83 & $\mathrm{Rp} 2,104,244,679.51$ & Rp10,805,228.58 & Rp2,298,843,975.38 \\
\hline Oktober & Rp10,647,199.57 & Rp1,795,985,073.20 & Rp11,033,785.53 & Rp2,456,805,193.22 \\
\hline November & Rp10,473,313.60 & Rp1,647,323,741.09 & Rp11,609,385.75 & $\mathrm{Rp} 2,384,615,380.25$ \\
\hline Desember & Rp10,575,414.87 & Rp1,715,137,481.50 & Rp11,511,089.96 & Rp2,331,497,206.71 \\
\hline
\end{tabular}

\begin{tabular}{|l|c|c|c|c|}
\hline \multirow{2}{*}{$\begin{array}{c}\text { Tahun } \\
\text { Bulan }\end{array}$} & \multicolumn{2}{|c|}{2014} & \multicolumn{2}{c|}{2015} \\
\cline { 2 - 6 } & Bagi Hasil & $\begin{array}{c}\text { Simpanan } \\
\text { Judharabah }\end{array}$ & Bagi Hasil & $\begin{array}{c}\text { Simpanan } \\
\text { Mudharabah }\end{array}$ \\
\hline Februari & $\mathrm{Rp} 12,535,546.81$ & $\mathrm{Rp} 2,616,400,371.95$ & $\mathrm{Rp} 4,371,528.96$ & $\mathrm{Rp} 4,098,980,376.23$ \\
\hline Maret & $\mathrm{Rp} 13,852,415.20$ & $\mathrm{Rp} 3,128,432,090.75$ & $\mathrm{Rp} 17,231,964.80$ & $\mathrm{Rp} 4,220,339,003.47$ \\
\hline April & $\mathrm{Rp} 14,318,700.57$ & $\mathrm{Rp} 3,366,060,593.62$ & $\mathrm{Rp} 17,730,255.32$ & $\mathrm{Rp} 4,675,129,357.16$ \\
\hline Mei & $\mathrm{Rp} 14,592,690.04$ & $\mathrm{Rp} 3,353,194,503.06$ & $\mathrm{Rp} 18,213,590.21$ & $\mathrm{Rp} 4,656,663,173.98$ \\
\hline Juni & $\mathrm{Rp} 14,745,374.01$ & $\mathrm{Rp} 3,303,197,730.25$ & $\mathrm{Rp} 17,648,403.24$ & $\mathrm{Rp} 4,570,625,461.88$ \\
\hline Juli & $\mathrm{Rp} 12,742,834.28$ & $\mathrm{Rp} 2,474,675,928.15$ & $\mathrm{Rp} 16,104,008.63$ & $\mathrm{Rp} 2,728,485,183.98$ \\
\hline Agustus & $\mathrm{Rp} 13,368,240.13$ & $\mathrm{Rp} 3,135,006,312.93$ & $\mathrm{Rp} 16,242,996.09$ & $\mathrm{Rp} 4,307,304,643.94$ \\
\hline September & $\mathrm{Rp} 13,034,720.54$ & $\mathrm{Rp} 3,756,376,118.58$ & $\mathrm{Rp} 16,618,766.95$ & $\mathrm{Rp} 4,151,485,103.43$ \\
\hline Oktober & $\mathrm{Rp} 13,656,076.82$ & $\mathrm{Rp} 3,502,378,697.91$ & $\mathrm{Rp} 18,028,907.11$ & $\mathrm{Rp} 3,728,632,593.96$ \\
\hline November & $\mathrm{Rp} 14,465,639.05$ & $\mathrm{Rp} 3,278,498,646.54$ & $\mathrm{Rp} 17,844,154.47$ & $\mathrm{Rp} 3,874,942,068.25$ \\
\hline Desember & $\mathrm{Rp} 14,778,985.25$ & $\mathrm{Rp} 3,773,451,794.43$ & $\mathrm{Rp} 17,926,360.71$ & $\mathrm{Rp} 3,672,666,259.90$ \\
\hline
\end{tabular}

\begin{tabular}{|l|c|c|}
\hline \multirow{2}{*}{ Tahun } & \multicolumn{2}{|c|}{2016} \\
\cline { 2 - 3 } Bulan & Bagi Hasil & $\begin{array}{c}\text { Simpanan } \\
\text { Mudharabah }\end{array}$ \\
\hline Januari & $\mathrm{Rp} 18,232,625.40$ & $\mathrm{Rp} 4,091,714,790.12$ \\
\hline Februari & $\mathrm{Rp} 14,519,255.12$ & $\mathrm{Rp} 3,434,951,792.57$ \\
\hline Maret & $\mathrm{Rp} 18,444,756.30$ & $\mathrm{Rp} 4,244,155,797.03$ \\
\hline April & $\mathrm{Rp} 15,306,253.91$ & $\mathrm{Rp} 4,273,487,768.59$ \\
\hline Mei & $\mathrm{Rp} 18,642,612.63$ & $\mathrm{Rp} 3,297,273,885.78$ \\
\hline Juni & $\mathrm{Rp} 17,454,432.41$ & $\mathrm{Rp} 3,291,667,874.81$ \\
\hline Juli & $\mathrm{Rp} 15,142,238.64$ & $\mathrm{Rp} 2,773,319,062.22$ \\
\hline Agustus & $\mathrm{Rp} 17,951,575.44$ & $\mathrm{Rp} 4,881,506,072.42$ \\
\hline September & $\mathrm{Rp} 13,519,638.01$ & $\mathrm{Rp} 3,617,121,412.90$ \\
\hline Oktober & $\mathrm{Rp} 7,997,777.00$ & $\mathrm{Rp} 3,708,307,585.49$ \\
\hline November & $\mathrm{Rp} 27,699,613.00$ & $\mathrm{Rp} 3,528,571,052.20$ \\
\hline Desember & $\mathrm{Rp} 16,188,474.00$ & $\mathrm{Rp} 3,435,105,417.06$ \\
\hline
\end{tabular}

Data perubahan Bagi Hasil dan Simpanan mudharabah KSPPS BMT Amanah Ray Medan dari tahun 2012 sampai dengan 2016, dapat disajikan sebagai berikut ini:

Tabel 2 Data Perubahan Bagi Hasil Dan Simpanan Mudharabah Periode : 2012-2016

\begin{tabular}{|c|c|c|c|c|c|c|c|c|c|c|}
\hline \multirow{4}{*}{ Tahun } & \multicolumn{2}{|c|}{2012} & \multicolumn{2}{|c|}{2013} & \multicolumn{2}{c|}{2014} & \multicolumn{2}{c|}{2015} & \multicolumn{2}{c|}{2016} \\
\cline { 2 - 9 } & Bag & Simpana & Bag & Simpana & Bag & Simpana & Bag & Simpana & Bag & Simpana \\
\cline { 2 - 7 }
\end{tabular}




\begin{tabular}{|c|c|c|c|c|c|c|c|c|c|c|}
\hline Bulan & $\begin{array}{c}\text { i } \\
\text { Has } \\
\text { il }\end{array}$ & $\begin{array}{c}\mathrm{n} \\
\text { Mudhara } \\
\text { bah }\end{array}$ & $\begin{array}{c}\mathrm{i} \\
\text { Has } \\
\text { il }\end{array}$ & $\begin{array}{c}\mathrm{n} \\
\text { Mudhara } \\
\text { bah }\end{array}$ & $\begin{array}{c}\text { i } \\
\text { Has } \\
\text { il }\end{array}$ & $\begin{array}{c}\mathrm{n} \\
\text { Mudhara } \\
\text { bah }\end{array}$ & $\begin{array}{c}\text { i } \\
\text { Has } \\
\text { il }\end{array}$ & $\begin{array}{c}n \\
\text { Mudhara } \\
\text { bah }\end{array}$ & $\begin{array}{c}\text { i } \\
\text { Has } \\
\text { il }\end{array}$ & $\begin{array}{c}\mathrm{n} \\
\text { Mudhara } \\
\text { bah }\end{array}$ \\
\hline Januari & $\begin{array}{l}16 . \\
12\end{array}$ & 21.33 & $\begin{array}{l}16 . \\
27\end{array}$ & 21.36 & $\begin{array}{l}16 . \\
34\end{array}$ & 21.69 & $\begin{array}{l}15 . \\
29\end{array}$ & 22.13 & $\begin{array}{l}16 . \\
72\end{array}$ & 22.13 \\
\hline $\begin{array}{l}\text { Februar } \\
\text { i }\end{array}$ & $\begin{array}{l}16 . \\
18\end{array}$ & 21.32 & $\begin{array}{l}16 . \\
18\end{array}$ & 21.17 & $\begin{array}{l}16 . \\
44\end{array}$ & 21.86 & $\begin{array}{l}16 . \\
66\end{array}$ & 22.16 & $\begin{array}{l}16 . \\
49\end{array}$ & 21.96 \\
\hline Maret & $\begin{array}{l}16 . \\
21\end{array}$ & 21.23 & $\begin{array}{l}16 . \\
19\end{array}$ & 21.21 & $\begin{array}{l}16 . \\
45\end{array}$ & 21.78 & $\begin{array}{l}16 . \\
65\end{array}$ & 22.15 & $\begin{array}{l}16 . \\
73\end{array}$ & 22.17 \\
\hline April & $\begin{array}{l}16 . \\
26\end{array}$ & 21.33 & $\begin{array}{l}16 . \\
19\end{array}$ & 21.3 & $\begin{array}{l}16 . \\
48\end{array}$ & 21.94 & $\begin{array}{l}16 . \\
69\end{array}$ & 22.27 & $\begin{array}{l}16 . \\
54\end{array}$ & 22.18 \\
\hline Mei & $\begin{array}{l}16 . \\
26\end{array}$ & 21.38 & $\begin{array}{l}16 . \\
02\end{array}$ & 21.34 & $\begin{array}{c}16 . \\
5\end{array}$ & 21.93 & $\begin{array}{l}16 . \\
72\end{array}$ & 22.26 & $\begin{array}{l}16 . \\
74\end{array}$ & 21.92 \\
\hline Juni & $\begin{array}{l}16 . \\
23 \\
\end{array}$ & 21.42 & $\begin{array}{l}16 . \\
28 \\
\end{array}$ & 21.31 & $\begin{array}{l}16 . \\
51\end{array}$ & 21.92 & $\begin{array}{l}16 . \\
69 \\
\end{array}$ & 22.24 & $\begin{array}{l}16 . \\
68 \\
\end{array}$ & 21.91 \\
\hline Juli & $\begin{array}{l}16 . \\
22\end{array}$ & 21.33 & $\begin{array}{l}16 . \\
08\end{array}$ & 21.25 & $\begin{array}{l}16 . \\
36\end{array}$ & 21.63 & $\begin{array}{l}16 . \\
59\end{array}$ & 21.73 & $\begin{array}{l}16 . \\
53\end{array}$ & 21.74 \\
\hline $\begin{array}{l}\text { Agustu } \\
\text { S }\end{array}$ & $\begin{array}{l}16 . \\
12\end{array}$ & 21.09 & $\begin{array}{c}16 . \\
2\end{array}$ & 20.89 & $\begin{array}{l}16 . \\
41\end{array}$ & 21.87 & $\begin{array}{c}16 . \\
6\end{array}$ & 22.18 & $\begin{array}{c}16 . \\
7\end{array}$ & 22.31 \\
\hline $\begin{array}{l}\text { Septem } \\
\text { ber }\end{array}$ & $\begin{array}{l}16 . \\
34\end{array}$ & 21.47 & $\begin{array}{c}16 . \\
2\end{array}$ & 21.56 & $\begin{array}{l}16 . \\
38\end{array}$ & 22.05 & $\begin{array}{l}16 . \\
63\end{array}$ & 22.15 & $\begin{array}{l}16 . \\
42\end{array}$ & 22.01 \\
\hline $\begin{array}{l}\text { Oktobe } \\
\text { r }\end{array}$ & $\begin{array}{l}16 . \\
18\end{array}$ & 21.31 & $\begin{array}{l}16 . \\
22\end{array}$ & 21.62 & $\begin{array}{l}16 . \\
43\end{array}$ & 21.98 & $\begin{array}{l}16 . \\
71\end{array}$ & 22.04 & $\begin{array}{l}15 . \\
89\end{array}$ & 22.03 \\
\hline $\begin{array}{l}\text { Novem } \\
\text { ber }\end{array}$ & $\begin{array}{l}16 . \\
16 \\
\end{array}$ & 21.22 & $\begin{array}{l}16 . \\
27\end{array}$ & 21.59 & $\begin{array}{l}16 . \\
49\end{array}$ & 21.91 & $\begin{array}{c}16 . \\
7\end{array}$ & 22.08 & $\begin{array}{l}17 . \\
14\end{array}$ & 21.98 \\
\hline $\begin{array}{l}\text { Desem } \\
\text { ber }\end{array}$ & $\begin{array}{l}16 . \\
17\end{array}$ & 21.26 & $\begin{array}{l}16 . \\
26\end{array}$ & 21.57 & $\begin{array}{l}16 . \\
51\end{array}$ & 22.05 & $\begin{array}{c}16 . \\
7\end{array}$ & 22.02 & $\begin{array}{c}16 . \\
6\end{array}$ & 21.96 \\
\hline
\end{tabular}

\section{Uji Regresi Linier Sederhana}

Instrumen yang digunakan dalam penelitian ini adalah laporan jumlah bagi hasil dan simpanan mudharabahperiode tahun 2012 sampai dengan 2016. Data ini berisikan tahun, jumlah bagi hasil dan jumlah simpanan mudharabah.

Tabel 3 Hasil Uji Regresi Linier Sederhana

\section{Coefficients $^{a}$}

\begin{tabular}{|c|c|c|c|c|c|c|}
\hline \multirow{2}{*}{\multicolumn{2}{|c|}{ Model }} & \multicolumn{2}{|c|}{$\begin{array}{c}\text { Unstandardized } \\
\text { Coefficients }\end{array}$} & \multirow{2}{*}{$\begin{array}{c}\text { Standardized } \\
\text { Coefficients } \\
\text { Beta }\end{array}$} & \multirow[b]{2}{*}{$\mathrm{t}$} & \multirow[b]{2}{*}{ Sig. } \\
\hline & & $\mathrm{B}$ & Std. Error & & & \\
\hline & (Constant) & 8.730 & 2.358 & & 3.701 & .000 \\
\hline & $\begin{array}{l}\text { Bagi Hasil } \\
\text { (X) }\end{array}$ & .793 & .144 & .587 & 5.516 & .000 \\
\hline
\end{tabular}

a. Dependent Variable: Simpanan Mudharabah(Y)

Berdasarkan hasil pengujian diatas, maka diperoleh persamaan regresi sebagai berikut:

$$
Y=8.730+0.793 x
$$

Pada model regresi linier sederhana diperoleh nilai konstanta bagi hasil sebesar 8.730 artinya jika nilai variabel bebas (X) nilainya 0 , maka variabel terikat (Y) nilainya sebesar 8.730. Koefisien regresi variabel bebas benilai positif, artinya simpanan mudharabahdapat dipengaruhi oleh bagi hasil. 


\section{Pengujian Hipotesis}

a. Uji Determinasi $\left(\mathrm{R}^{2}\right)$

Koefisien Determinasi $\left(\mathrm{R}^{2}\right)$ pada intinya mengukur seberapa kemampuan model dalam menerangkan variabel terikat. Nilai koefisien determinasi pada penelitian ini dapat dilihat pada table berikut:

Tabel 4 Uji Koefisien Determinasi $\left(\mathrm{R}^{2}\right)$

\begin{tabular}{|l|c|r|r|r|}
\multicolumn{7}{|c}{ Model Summary } \\
\hline Model & $\mathrm{R}$ & R Square & $\begin{array}{c}\text { Adjusted R } \\
\text { Square }\end{array}$ & $\begin{array}{c}\text { Std. Error of } \\
\text { the Estimate }\end{array}$ \\
\hline 1 & $.587^{\mathrm{a}}$ & .344 & .333 & .30626 \\
\hline
\end{tabular}

a. Predictors: (Constant), $\mathrm{X}$

Nilai koefisien Determinasi $\left(\mathrm{R}^{2}\right)$ yang diperoleh 0.344 atau sama dengan $34.4 \%$ menunjukan bahwa variabel bagi hasil mampu menjelaskan variasi yang terjadi terhadap simpanan mudharabahpada KSPPS BMT Amanah Ray Medan, sedangkan sisanya sebesar 65.6\% dijelaskan oleh variabel lain yang tidak diteliti dalam penelitian ini.

b. Uji Parsial (Uji t)

Uji Parsial (Uji t) bertujuan untuk melihat pengaruh bagi hasil (X) secaraparsial terhadap simpanan mudharabah (Y), pengujian dilakukan pada tingkat kesalahan $\alpha=0.05(5 \%)$ dengan kriteria:

1) Jika $t_{\text {hitung }} \leq \mathrm{t}_{\text {tabel }}$, maka $\mathrm{H}_{0}$ diterima, $\mathrm{H}_{1}$ ditolak, artinya secara parsial penelitian ini tidak ada pengaruh;

2) Jika $t_{\text {hitung }}>t_{\text {tabel }}$, maka $\mathrm{H}_{0}$ ditolak, $\mathrm{H}_{1}$ diterima, artinya secara parsial penelitian iniada pengaruh;

Tabel 5 Hasil Uji Parsial ( uji t )

Coefficients $^{\mathrm{a}}$

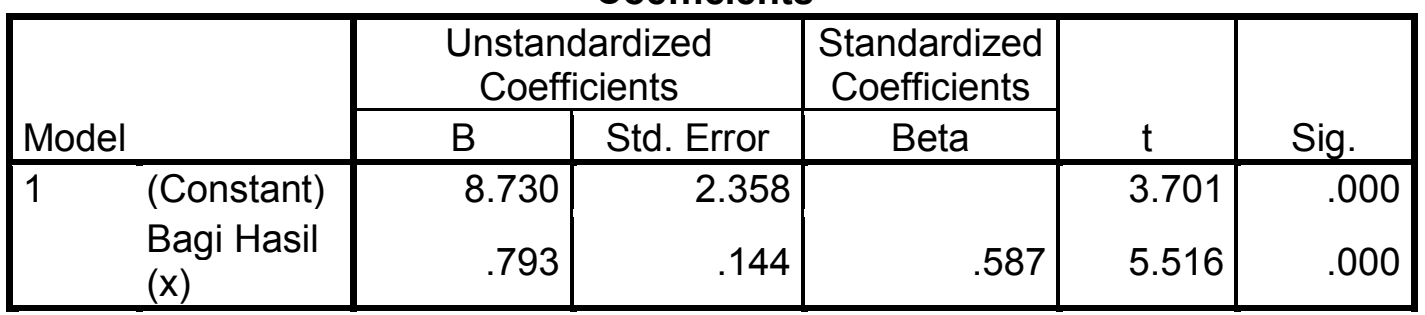

a. Dependent Variable: Simpanan Mudharabah (Y)

Berdasarkan tabel tersebut dapat dilihat bahwa:

Nilai $\mathrm{t}_{\text {hitung }}$ untuk variabel bagi hasil $5.516 \geq$ dari $\mathrm{t}_{\text {tabel }} 2.00172$ dan nilai sig $0.000 \leq$ dari alpha 0.05 , maka $\mathrm{H}_{0}$ ditolak, $\mathrm{H}_{1}$ diterima.Hasil uji parsial diatas menunjukan bahwa secara parsial bagi hasil berpengaruh positif dan signifikan terhadap simpananmudharabah.

\section{Pembahasan}

Hasil pengujian hipotesis pertama menunjukan bahwa bagi hasil mampu menjelaskan variasi yang terjadi pada simpanan mudharabah pada KSPPS BMT Amanah Ray Medan, ini dibuktikan dengan nilai koefisien determinasi yang diperoleh 0.344 atau sama dengan $34.4 \%$, sedangkan sisanya sebesar $65.6 \%$ dijelaskan oleh variabel lain yang tidak diteliti dalam penelitian ini.

Hasil pengujian hipotesis kedua menunjukan secara parsial bahwa bagi hasil berpengaruh positif dan signifikan terhadap simpanan mudharabah, ini dibuktikan dengan nilai $\mathrm{t}_{\text {hitung }}$ untuk variabel bagi hasil $5.516 \geq$ dari $\mathrm{t}_{\text {tabel }} 2.00172 \mathrm{dan}$ nilai sig $0.000 \leq$ dari alpha 0.05 . hasil penelitian ini sesuai dengan penelitian yang dilakukan oleh Aziz (2014) dan Rachman dkk (2013) menyatakan bahwa tingkat bagi hasil berpengaruh positif terhadap simpanan mudharabah. 


\section{KESIMPULAN}

Berdasarkan hasil penelitian dan pembahasan pada bab sebelumnya, maka dapat disimpulkan bahwa secara parsial variabel bagi hasil berpengaruh positif dan signifikan terhadap simpanan mudharabah pada KSPPS BMT Amanah Ray Medan hal ini memberi arti bahwa apabila semakin tinggi bagi hasil maka akan semakin tinggi juga simpanan mudharabah pada KSPPS BMT Amanah Ray Medan, begitu juga sebaliknya semakin rendah tingkat bagi hasil maka simpanan mudharabah akan menurun. Berdasarkan hasil analisis determinasi yang telah dilakukan, diperoleh nilai koefisien determinasi sebesar 0.344 Nilai ini berarti bahwa sebesar $34.4 \%$ bagi hasil mampu menjelaskan variasi yang terjadi pada simpanan mudharabah pada KSPPS BMT Amanah Ray Medan yang diamati selama periode 2012-2016 dipengaruhi oleh tingkat bagi hasil dari perusahaan tersebut, sedangkan sisanya sebesar $65.6 \%$ dipengaruhi oleh variabel lain yang tidak diteliti dalam penelitian ini. 


\section{REFERENCES}

Abdullah, T., \& Tantri, F. (2014). Bank dan Lembaga Keuangan (3rd ed.). Jakarta: PT. Rajagrafindo Persada.

Abdullah, T., \& Tantri, F. (2014). Bank dan Lembaga Keuangan Syariah. jakarta: PT. Rajagrafindo Persada.

Alma, B., \& Donni Juni Priansa. (2014). Manajemen Bisnis Syariah. (R. Somad, Ed.) (2nd ed.). CV. Alfabeta.

Aziz. (2014). Pengaruh Tingkat Bagi Hasil Terhadap Simpanan Mudharabah Pada PT. Bank Muamalat Indonesia TBK, 13.

Dewianty, S. (2013). Sekolah Tinggi Agama Islam Darul Ulum Banyuwangi. Jurnal Ekonomi Dan Hukum Islam, 3(2), 94-116.

Fordebi. (2016). Ekonomi dan Bisnis Islam (1st ed.). Jakarta: PT. Rajagrafindo Persada.

Kasmir. (2014). Bank dan Lembaga Keuangan Lainnya. Jakarta: PT. Rajagrafindo Persada.

Menteri. (2007). Peraturan Menteri Negara Koperasi dan Usaha kecil dan Menengah Republik Indonesia, 1-39.

Muhammad. (2014). Sistem Bagi Hasil dan Pricing Bank Syariah. UII Press.

Natalia, E., Dzulkirom, M. A., \& Mangesti, S. R. (2014). Pengaruh Tingkat Bagi Hasil Deposito bank Syariah dan Suku Bunga Deposito bank Umum Terhadap Jumlah Simpanan Deposito Mudharabah. Jurnal Administrasi Bisnis, 9(1), 1-7.

Nofinawati. (2014). Akad dan Produk Perbankan Syariah, 155-176.

Nurhayati, S., \& Wasilah. (2015). Akuntansi Syariah di Indonesia (Ke-4). Jakarta: Selembah Empat.

Pristiyanto, Mochamad, H. B., \& Soekarto, S. T. (2013). Strategi Pengembangan Koperasi Jasa Keuangan Syariah Dalam Pembiayaan Usaha Mikro di Kecamatan Tanjungsari, Sumedang, $8(1), 27-35$.

Rachman, R. A., Yulianto, A., \& Utaminingsih, N. S. (2013). Pengaruh Bagi Hasil, Bunga, Ukuran Bank dan Jumlah Cabang Terhadap Simpanan Mudharabah. Accounting Analysis Journal, 2(4), 413-422.

Soemitra. (2016). Bank dan Lembaga Keuangan Syariah (Ke-Dua). Jakarta: KENCANA.

Sunyoto, D. (2016). Metodologi Penelitian Akuntansi. (A. Gunarsa, Ed.) (2nd ed.). PT. Refika Aditama.

Supriyanto. (2015). Tata Kelola Koperasi Kredit atau Koperasi Simpan Pinjam. (A. Pramesta, Ed.). Yogyakarta: CV Andi Offset.

Timami, M. F., \& Soejoto, A. (2013). SYARIAH MANDIRI DI INDONESIA. 
Yusuf, M. (2015). Metode Penelitian Kuantitatif, Kualitatif dan penelitian Gabungan (ke-2). Jakarta: Prenadamedia Group. 